\title{
SYNERGISTIC THERAPEUTIC EFFECT OF HONOKIOL AND 5-FLUOROURACIL ON THE INDUCED-TONGUE CANCER IN RATS
}

\author{
Sara Ali Swidan ${ }^{1}$, Magda Mohamed Aly Hassan², Merhan N. Elmansy ${ }^{3}$
}

DOI: $10.21608 / d s u .2021 .27204 .1035$

Manuscript ID: DSU-2004-1035 (R4)

\section{KEYWORDS}

Fluorouracil, Honokiol,

OSCC, P53, PCR.

- E-mail address: sara.swidan@yahoo.com

1. Assistant lecturer in the Department of Oral Pathology, Faculty of Dentistry, Suez Canal University, Ismailia, Egypt.

2. Professor in the Department of Oral Pathology, Faculty of Dentistry, Suez Canal University, Ismailia, Egypt.

3. Lecturer in the Department of Oral Pathology, Faculty of Dentistry, Suez Canal University, Ismailia, Egypt.

\begin{abstract}
Introduction: 5-Fluorouracil (5-FU) is a common chemotherapeutic drug for treatment of oral squamous cell carcinoma. However, its toxicity to normal tissues has limited its role as an effective cancer therapy. Aim: This research aimed to investigate the effect of combining 5-FU with honokiol (HNK) on enhancing the anticancer activity of 5-FU without increasing its toxicity. Material and methods: HNK was used in combination with 5-FU for treatment of tongue carcinoma induced chemically by 4-nitroquinoline 1 oxide (4-NQO) in albino rats. Rats were divided into five groups (10 animals each) including control, 4-NQO, 5-FU, HNK, and combined 5-FU with HNK. Serial sections of the tongues from all animals were examined microscopically and real-time PCR quantification of P53 gene expression was also assessed. Results: The results showed that treatment with both 5-FU + HNK had significantly regressed the number and size of malignant lesions seen in the carcinogen-only group. Data analysis revealed a statistically significant decrease in the expression levels of mutant P53 in the combined treatment group compared to control groups. Conclusion: This study reported that HNK and 5-FU had a synergistic cytotoxic effect on this model, without notable intensification of the side effects associated with 5-FU treatment.
\end{abstract}

\section{INTRODUCTION}

Oral cancer refers to a subgroup of head and neck malignancies that develop at the tongue, salivary glands, lips, gingiva, floor of the mouth, buccal surfaces, palate, and oropharynx ${ }^{(1)}$. It is the sixth most common cancer worldwide and among the top three leading malignancies accounting about 300,000 new cases diagnosed annually ${ }^{(2)}$. Importantly, the crude incidence and mortality rates of oral cancer are projected to double by 2030 especially in Egypt, Iran, Morocco, Sudan, and Turkey ${ }^{(3)}$.

The most commonly used animal model to induce tongue carcinoma is the rat, through using $4 \mathrm{NQO}$ in the drinking water for 20 weeks ${ }^{(4)}$. Chronic administration of $4 \mathrm{NQO}$ stimulates rat tongue carcinogenesis in the same manner that occurs in humans, in terms of initiation, promotion, and progression ${ }^{(5)}$. Chemotherapy is one of the most common treatment modalities that can be considered as a first choice, especially in patients who cannot tolerate surgical interventions. One of the most commonly used chemotherapeutic agents is 5-Fluoro-2, $4(1 \mathrm{H}$, 
$3 \mathrm{H})$ pyrimidinedione (5-FU) (commercial name: Fluorouracil). It is a pyrimidine analogue that was first described in 1957 and has remained an essential chemotherapeutic drug for a number of solid tumors, including oral squamous cell carcinoma $(\mathrm{OSCC})^{(6)}$. The intracellular metabolites of 5-FU exert cytotoxic effects via their incorporation into RNA and DNA, or through the inhibition of thymidylate synthetase, in turn, lead to activation of apoptosis. However, systemic use of 5-FU leads to significant toxic side effects that accompanies tumor therapy, with development of drug resistance. This subsequently have limited the role of $5-\mathrm{FU}^{(6}$ ${ }^{7}$.Combination of different chemotherapeutic agents that work through different molecular pathways is a growing strategy aiming to enhance the effect of chemotherapy and lowering systemic toxicity to a minimal level ${ }^{(8)}$.

Honokiol (HNK) is a pure biphenyl compound isolated from Magnolia species (Magnolia officinalis) extracts, which is commonly used as a medicinal herb in traditional Chinese medicine. HNK has anti-inflammatory, antibacterial, antifungal and antioxidant effects ${ }^{(9)}$. It also has anticancer effects against different types of cancer mainly through induction of apoptosis ${ }^{(9,10)}$.

P53 is one of the most intensively studied tumor suppressor proteins. Mutations of the P53 gene that lead to loss of wild-type P53 activity. Disturbances in P53 signaling pathways are believed to be required for the development of most cancers, and there is evidence to suggest that restoration or reactivation of P53 function will have significant therapeutic benefits ${ }^{(11)}$. Most OSCC were found to be associated with mutations of the P53 gene ${ }^{(12)}$. Mutation of the P53 inhibits the tumor suppressor functions of the wild-type P53 and also acquires the mutant protein with new activities ${ }^{(13)}$. The synergism achieved by using a phytochemical that has an antitumor effect and exerts no toxic side effects with 5-FU may enhance its cytotoxic effect without increasing its toxicity to normal tissue / organs. This subsequently allows for use of a lower drug concentration and further reduction of its toxic side effects.

\section{MATERIALS AND METHODS}

\section{Experimental design}

[Approval of the research ethical committee (REC), Faculty of Dentistry, Suez Canal University was obtained before starting the study].

The sample size was calculated using the following formula using a confidence level of $95 \%$ and confidence interval of 2.5 .

$$
\text { sample size }=\frac{z^{2 *(P) *(1-p)}}{c^{2}}
$$

Where:

$* \mathrm{Z}=\mathrm{z}$ value

*P=proportion of the population having the attribute

$* \mathrm{C}=$ Confidence interval, expressed as decimal.

So by calculation, the sample size was equal to 10 animals per group, giving a total sample size of 50 animals.

Fifty male Wistar albino rats with mean weight of $150 \mathrm{gm}$ were used in this experiment. They were divided into 5 main groups (10 animals each): Group (1): Negative control group, were given regular tap water only for 24 weeks. Group (2): Positive control group, were given 4NQO $(0.002 \%)$ in drinking water for 20 weeks, then regular tap water for 4 weeks. Group (3): The animals were given 4NQO (0.002\%) as in G2, then, injected with $5-F U,(40 \mathrm{mg} / \mathrm{kg} /$ day), three times/week for 4 weeks, 
i.p. Group (4): The animals were given $4 \mathrm{NQO}$ $(0.002 \%)$ as in $\mathrm{G} 2$, then, injected with HNK, $(20 \mathrm{mg} /$ $\mathrm{kg} /$ day), three times/week for 4 weeks, i.p. Group (5): The animals were given $4 \mathrm{NQO}(0.002 \%)$ as in $\mathrm{G} 2$, then injected with both $5-\mathrm{FU}(40 \mathrm{mg} / \mathrm{kg} /$ day) and HNK $(20 \mathrm{mg} / \mathrm{kg} / \mathrm{day})$, three times/week for 4 weeks, i.p. All rats were euthanized on the $40^{\text {th }}$ day after chemotherapeutic drugs administration, and a snap from the dissected tongue was kept in $-80^{\circ} \mathrm{C}$ for RT-qPCR (for detection of mutant P53 gene). The remaining tongue tissues were fixed overnight in buffered $10 \%$ formalin then embedded in paraffin. Serial longitudinal sections (anteroposterior) of $5 \mu$ thickness were prepared with routine hematoxylin and eosin $(\mathrm{H} \& \mathrm{E})$. The vital organs of the experimental animals were evaluated for gross changes.

\section{Real time-quantitative Polymerase chain reaction (RT-qPCR)}

Briefly, total RNA extracted from homogenized fine powder of removed tongue tissues as described in detail by Chomczynski and Sacchi method ${ }^{(14)}$. RNA was reverse transcribed to cDNA using Revert Aid first strand cDNA synthesis kit (Thermo Fisher Scientific, USA, \#cat EP0442). The resulting cDNA was diluted 1:30 fold and the PCR reaction were performed with $2 \mu \mathrm{l}$ cDNA. Reaction volume was $12.5 \mu \mathrm{l}, 5 \mu \mathrm{g}$ RNA sample (in $\mathrm{X} \mu \mathrm{l}$ ) was taken and completed into $11.5 \mu \mathrm{l}$ with DEPC treated water. 0.5 $\mu \mathrm{l}$ Random primer and $0.5 \mu \mathrm{l}$ oligo dT were added. Their working concentration was $10 \mu \mathrm{M}$. Master Mix of reverse transcriptase was prepared in a new tube by adding $4 \mu \mathrm{l}$ of MMLV buffers (5X), $2 \mu \mathrm{l}$ of dNTP's Mixture (10mM each), $0.5 \mu$ of RNase inhibitor $(40 \mathrm{u} / \mu \mathrm{l})$ and $1 \mu \mathrm{l}$ of MMLV-RTase $(20 \mathrm{u} / \mu \mathrm{l})$, the total volume was $7.5 \mu \mathrm{l}$. cDNA samples were diluted tenfold before introducing into qPCR reaction and each one was processed as triplet set. All pipetting was performed with filter tips and the reaction mixture was prepared by adding $4 \mu \mathrm{l}$ Sybr Green qPCR Master Mixture (HOT FIREPol EvaGreen qPCR Mix Plus 5X), $0.5 \mu l$ forward primer $(10 \mathrm{mM})$, $0.5 \mu$ l reverse primer $(10 \mathrm{mM}), 1 \mu \mathrm{l}$ diluted cDNA template and filled up $20 \mu \mathrm{l}$ with nuclease free water. The qPCR was performed according to the following program: Initial denaturation and polymerase activation step for 2 minutes at $95^{\circ} \mathrm{C}$, denaturation step at $95^{\circ} \mathrm{C}$ for 15 seconds, annealing step for 30 seconds at $60^{\circ} \mathrm{C}$. Denaturation, annealing and elongation steps were performed 60 cycles. The following rat primers were used: P53 "CCCTGGCACCTACAATGAAA" (Forward), "GCTTTGCAGAATGGAAGGAAAG" (Reverse). GAPDH "TCACCACCATGGAGAAGGC" (Foreword)," GCTAAGCAGTTGGTGGTGCA" (Reverse). The data were statistically analyzed using One-Way Analysis of Variance (ANOVA) via SPSS ${ }^{\circledR} 22$ (IBM, New York, USA).

\section{RESULTS}

\section{Clinico-pathologic findings}

In group "1" (Negative control), tongues of the control animals appeared normal without any change in color or architecture with no skin lesions, hair loss or mortality. In group "2" (4NQO- only), hair loss was seen mainly at the abdominal and neck region, with no skin lesions. Lesions detected on the surface of the tongue were either exophytic (protruding from the tongue) or endophytic (malignant ulcers) that varied in size, two mortalities were detected in this group (effective number of rats is 8 ). In Group "3" (5-FU only); tongues showed nodular masses that exhibited smaller sizes than group 2 with irregular surfaces. Skin ulcers, hair loss, liver lesions, and diarrhea were all noted. Two animals died in this group. In group "4" (HNK only); the lesions were large nodules at the base, dorsal and 
lateral surfaces of the tongue. No skin lesions, hair loss, or gastrointestinal tract (GIT) abnormalities were detected. Single mortality was detected in this group. In group "5" (HNK and FU); the tongue lesions were minute nodules at the dorsal surfaces. No GIT abnormalities, skin ulcers or hair loss were detected, with single mortality.

\section{Histological findings:}

In group (1), Tissue sections showed normal thin keratinized stratified squamous epithelium of filiform papillae covering dorsal surface of tongue, and underlying connective tissue was free of inflammatory cells. [Figure.1a] In Group (2), all the examined tongues showed invasive squamous cell carcinoma of different grades. Well, moderately and severely differentiated squamous cell carcinoma were recorded with invading islands are shown to destruct the underlying musculature. [Figure.1b] In group (3), mild, moderate, and severe dysplasia were recorded. Two tongues were recorded with well differentiated squamous cell carcinoma with multiple keratin pearls invading the underlying connective tissue. [Figure.1c] In group (4), mild, moderate, and severe dysplasia were recorded. Two tongues were recorded with well differentiated squamous cell carcinoma, and one with moderately differentiated SCC. [Figure.1d] In group (5), where the animals were injected with the combination drugs, nine tongues showed different grades of dysplasia, while one tongue showed well differentiated squamous cell carcinoma, with superficial invasion of the dysplastic epithelial island. [Figure.1e]

\section{Quantitative real time polymerase chain reaction (RT-qPCR) of P53 gene}

The expression levels of the P53 gene in the experimental groups were evaluated using RT-qPCR.
The mean values of the quantitation cycle $(\mathrm{Cq})$ were recorded for each group. Glyceraldehyd-3phosphate dehydrogenase (GAPDH) gene was used as a reference gene, accordingly, $\mathrm{Cq}$ values were normalized then statistically analyzed. Transcripts of p53 gene were the most abundant in group " 2 " (mean $\mathrm{Cq}=19.45 \pm 3.46$ ), followed by group " 4 " $(\mathrm{Cq}=36 \pm 2.05)$, then group " 3 " $\mathrm{Cq}=37.8 \pm 2.42)$, and were least abundant at group " 5 " $(\mathrm{Cq}=39.4 \pm 1.58)$ and group "1", $(\mathrm{Cq}=53.6 \pm 7.36)$.

The mean difference between groups was significant $(p \leq 0.05)$. There is significant decrease between all groups compared to group 1, in group 2 by $63.7 \%$, in group 3 by $29.4 \%$, and in group 4 by $30 \%$. There is significant increase between all groups compared to group 2. In group (1) by $175.5 \%$, in group 3 by $94.4 \%$, and in group 4 by 92.6\%. [Figure.2]

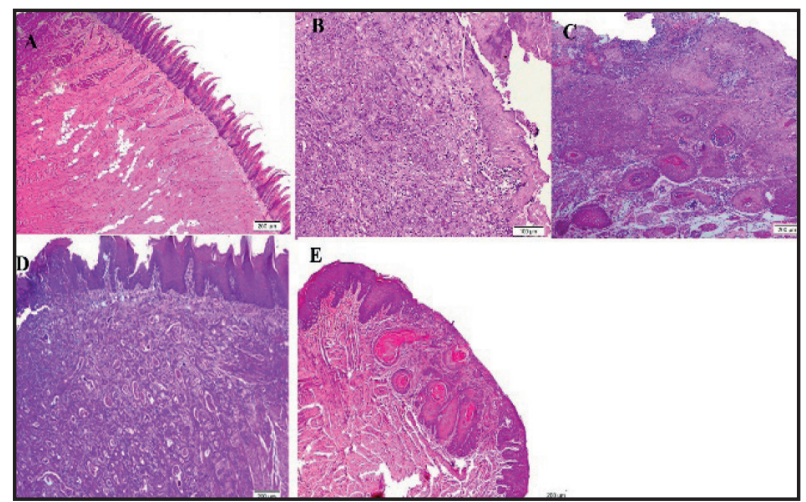

Fig. (1) Photomicrograph of H\&E stained sections of: (A): normal tongue mucosa in group 1 (untreated) (H\&Ex10), (B): invasion of dysplastic island into underlying connective tissue (moderately/poorly differentiated SCC) in group 2 (4NQO-only) (H\&Ex20), (C): superficial invasion with keratin pearls formation (well differentiated SCC) in group 3 (5-FU-only) (H\&Ex10), (D) well differentiated squamous cell carcinoma invading deep into underlying connective tissue in group 4 (HNK-only) (H\&Ex 10) (E) severe dysplastic criteria and superficial invasion in group 5 (5-FU and HNK) (H\&Ex10). 


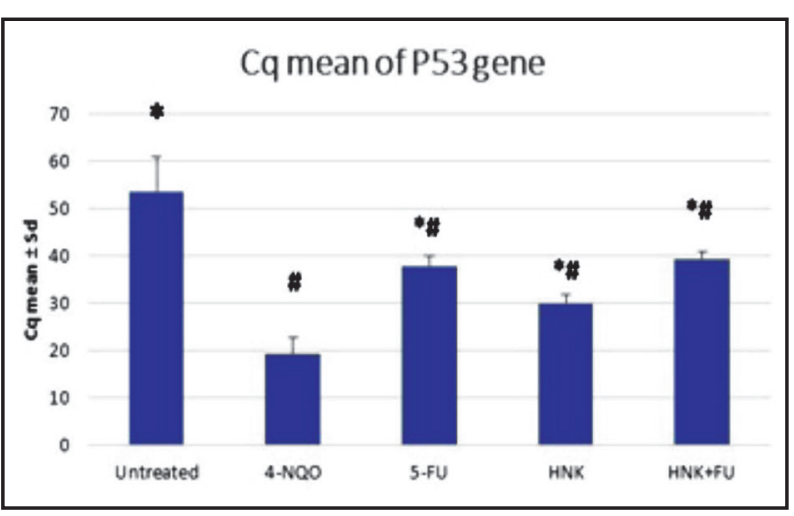

Fig. (2) Bar chart showing the mean score of $\mathrm{Cq}$ in the four groups.

Transcripts of $\mathrm{p} 53$ gene were the most abundant in group (2-carcinogen only) (mean $\mathrm{Cq}=19.45 \pm 3.46)$, whereas group (1, negative control) were the least abundant (mean $\mathrm{Cq}=53.6 \pm 7.36$ ). GAPDH was used as a reference gene.

\# $\mathrm{P}<0.05$ compared to control group

$* \mathrm{P}<0.05$ compared to 4-NQO group

\section{DISCUSSION}

This study aimed to investigate the possible effects of using the naturally occurring material "HNK" in combination with the popular chemotherapeutic drug "5-FU" in 4-NQO-rat tongue carcinogenesis model. The aim was to benefit the powerful synergistic antitumor effect of both 5-FU and HNK without any further increase in toxicity associated with the use of 5-FU. The results showed a marked regression of malignancy and improvement of the general health and clinical picture of the experimental animals treated with both 5-FU and HNK, if compared to those treated with either drug alone.

Induction of OSCC in tongue using 4NQO shows morphological and histopathological similarities to those of human tumors ${ }^{(15)}$. Also, the tongue is the most common intraoral site for cancer in most countries (16). Administration of drinking water containing 4-NQO was a simple and easy method in terms of the ease of handling and availability of rats. Importantly; it did not necessitate the extensive handling of both the animal and carcinogen.

In the research, the concentration of 20 p.p.m had produced clinically detectable lesions at the tongues by the end of the $20^{\text {th }}$ week. The lesions were mainly at the dorsal and lateral surfaces. This result was in agreement with Miyamoto et al. who reported that tongue and esophageal tumors developed in the rasH2 mice that received 4-NQO (20 p.p.m. in drinking water) by the end of the $20^{\text {th }}$ week $^{(17)}$. However, El-Rouby reported that tongue tumors were not induced before the $32^{\text {nd }}$ week of the experiment $^{(18)}$.

The clinical findings of the control group showed no clinical lesions, no hair loss or skin lesions and the physical activity of the animals was normal. Upon euthanization; tongues had normal histological features with no inflammatory, or atypical changes. These results were in agreement with other studies that reported the same findings on control group when the same model was used ${ }^{(4,19)}$.

The tongues of the animals administrated 4NQO exhibited papillomatous masses and indurated ulcers starting from $16^{\text {th }}$ week till end of induction period ( $20^{\text {th }}$ week). These findings were also described by Niwa $\boldsymbol{e t}$ al. who reported that apparent cancer formation was observed at almost the 20th week of the carcinogen administration ${ }^{(20)}$.

No skin lesions or eruptions were recorded in any group except for the 5-FU treated group (Group 3). Skin ulcers, hair loss, diarrhea and reduced physical activity of the treated animals 
were remarkable signs. These adverse effects and significant toxicity may be related to the mode of action of the 5-FU. 5-FU is proved to exert its cytotoxicity through alterations in protein and DNA synthesis. It inhibits the enzyme thymidine synthase (TS), the key to DNA synthesis ${ }^{(7)}$. In addition, 5-FU significantly increased expression of pro-inflammatory cytokines, such as IL-6, (COX-2) and TNF- $\alpha$, together with the generation of ROS by inducible nitric oxide synthase (iNOS). These significant peripheral toxicities are believed to arise from off-target specificity, targeting all rapidly dividing cells, like hair follicles, marrow cells and gastrointestinal epithelia ${ }^{(21)}$ Administration of HNK with 5-FU significantly reduced these side effects on the treated animals. Similar results were concluded by Yazbeck $\boldsymbol{e t}$ al., when 5-FU was administrated synergistically with muricid extract in rats ${ }^{(22)}$.

Co-administration of $\mathrm{HNK}$ and 5-FU had resulted in synergistic effects that may be attributed to marked potency in inducing cancer cell apoptosis by both 5-FU and HNK. Chen et al. reported same results in vitro and related them to the synergistic enhancement of apoptosis ${ }^{(23)}$.This synergism did not result in intensification of FU side effects. This may be attributed to the use of lower concentrations of both drugs. In particular, the dose of 5-FU (40 $\mathrm{mg} / \mathrm{kg}$ ) in this combination treatment was much lower than the $150 \mathrm{mg} / \mathrm{kg}$ dose used in previous studies $^{(24,25)}$ and $20 \mathrm{mg} / \mathrm{kg}$ of HNK was lower than the common $25 \mathrm{mg} / \mathrm{kg}$ therapeutic dosage used in other models ${ }^{(26)}$ Second reason is that HNK is a strong antioxidant, this could result in low toxicity exerted by the free HNK ${ }^{(27)}$. Comparable results were obtained by Pearson et al. who concluded that combing HNK with cetuximab (a popular chemotherapeutic drug) had overcome its resistance and intensified its effect without enhancing its toxicity ${ }^{(28)}$.
Third reason is concerned with the biological mechanisms of combining action of HNK with FU on the P53 gene. Oral carcinogenesis is commonly associated with mutations of the P53 gene, the level of which increases with oral cancer progression ${ }^{(11)}$. In the present study, the expression level of P53 was highest in the carcinogen-treated group, while its level was significantly decreased in the combination group. The same result was concluded by Latif $\boldsymbol{e t}$ al. as they addressed the expression levels of P53 when the chemically-induced colon cancer in rats was treated with 5-FU. They regarded the significant difference in P53 expression level between 5-FUtreated group and positive control group to several mechanisms. First, 5-FU can activate wild type p53. Second, incorporation of fluorouridine triphosphate into RNA, or incorporation of fluorodeoxyuridine triphosphate into DNA, in turn, inhibiting tymidine synthease (TS) by fluorodeoxyuridine monophosphate (FdUMP) with resultant DNA damage. They explained this effect as, both TS inhibition and mis-incorporation of 5-FU metabolites into RNA resulted in p53 stabilization ${ }^{(29)}$.

\section{CONCLUSION}

The present results revealed that HNK synergistically used with 5-FU had resulted in marked regression of malignancy and enhanced clinical therapeutic efficacy without significant increase in 5-FU toxic side effects. This result will permit using 5-FU in much lower doses, in turn will lead to significant reduction of its side effects.

\section{Declaration of Competing Interest}

Authors of this manuscript have no conflict of interest that may damage the integrity of the research. 


\section{REFERENCES}

1. Hamdy R, Halim A. Squamous cell carcinoma of the oral tongue: a single institution retrospective cohort study from Mansoura University Hospital. Indon J Can. 2019;12: 102-108.

2. Müller S. Update from the $4^{\text {th }}$ edition of the World Health Organization of head and neck tumours: tumours of the oral cavity and mobile tongue. Head Neck Pathol. 2017;11:33-40.

3. Bray F, Ferlay J, Soerjomataram I, Siegel RL, Torre LA, Jemal A. Global Cancer Statistics 2018: GLOBOCAN Estimates of Incidence and Mortality Worldwide for 36 Cancers in 185 Countries. CA: A Cancer J Clin 2018;68:394-424.

4. Khiavi MM, Rostami A, Hamishekar H, Abassi MM, Aghbali A, Salehi R, Abdollahi R, Soheila F, Sina M. Therapeutic efficacy of orally delivered doxorubicin nanoparticles in rat tongue cancer induced by 4-nitroquinoline 1-oxide. Advan Pharm Bull 2015;5:209-218.

5. Tanaka T, Kohno H, Sakata K, Yamada Y, Hirose Y, Sugie $\mathrm{S}$, Mori H. Modifying effects of dietary capsaicin and rotenone on 4-nitroquinoline 1-oxide-induced rat tongue carcinogenesis. Carcinogenesis 2002;23:1361-1367.

6. Lee JJ, Beumer JH, Chu E. Therapeutic drug monitoring of 5-fluorouracil. Cancer Chemother Pharmacol 2016;78:447-464.

7. Diasio RB, Harris BE. Clinical pharmacology of 5-fluorouracil. Clin Pharmacokinet 1989;16:215-237.

8. Liu H, Zang C, Emde A, Planas-Silva MD, Rosche M, Kühnl A, et al. Anti-tumor effect of honokiol alone and in combination with other anti-cancer agents in breast cancer. Eur J Pharmacol 2008;591:43-51.

9. Guo YB, Bao XJ, Xu SB, Zhang XD, Liu HY. Honokiol induces cell cycle arrest and apoptosis via p53 activation in H4 human neuroglioma cells. Int J Clin Exp Med 2015;8:7168-7177.

10. Huang JS, Yao CJ, Chuang SE, Yeh C-T, Lee LM, Chen R-M, Chao JW, Whang-Peng, J,Lai MJ. Honokiol inhibits sphere formation and xenograft growth of oral cancer side population cells accompanied with JAK/STAT signaling pathway suppression and apoptosis induction. BMC Cancer 2016;16:245-251.
11. Pentimalli F. Updates from the TP53 universe. Cell Death Differ 2018;25:10-2.

12. Roy AM, Baliga MS, Katiyar SK. Epigallocatechin-3gallate induces apoptosis in estrogen receptor-negative human breast carcinoma cells via modulation in protein expression of p53 and Bax and caspase-3 activation. Mol Cancer Ther 2005;4:81-90.

13. Muller PA, Vousden KH. p53 mutations in cancer. Nat Cell Biol 2013;15:2-9.

14. Chomczynski P, Sacchi N. Single-step method of RNA isolation by acid guanidinium thiocyanate-phenol-chloroform extraction. Anal Biochem 1987;162:156-159.

15. Ribeiro DA, Salvadori DMF. Gingival changes in wistar rats after oral treatment with 4-nitroquinoline 1-oxide. European J Dent 2007;1:152-159.

16. Fitzmaurice C, Allen C, Barber RM, Barregard L, Bhutta $\mathrm{ZA}$, Brenner $\mathrm{H}$, et al. Global, regional, and national cancer incidence, mortality, years of life lost, years lived with disability, and disability-adjusted life-years for 32 cancer groups, 1990 to 2015: a systematic analysis for the global burden of disease study. JAMA Oncol 2017;3:524-548.

17. Miyamoto S, Yasui Y, Kim M, Sugie S, Murakami A, Ishigamori-Suzuki R, Tanaka T. A novel ras H2 mouse carcinogenesis model that is highly susceptible to 4-NQOinduced tongue and esophageal carcinogenesis is useful for preclinical chemoprevention studies. Carcinogenesis 2008;29:418-426.

18. El-Rouby DH. Histological and immunohistochemical evaluation of the chemopreventive role of lycopene in tongue carcinogenesis induced by 4-nitroquinoline-1-oxide. Arch Oral Biol 2011;56:664-671.

19. Soares GR, de Moura CFG, Silva MJD, Vilegas W, Santamarina AB, Pisani LP, Estadella D, Ribeiro DA. Protective effects of purple carrot extract (Daucus carota) against rat tongue carcinogenesis induced by 4-nitroquinoline 1-oxide. Med Oncol. 2018;35:54-61.

20. Niwa $\mathrm{S}$, Ueno $\mathrm{S}$, Shirasu R. Alteration of $\mathrm{pRb}$ expression in the development of rat tongue carcinoma induced by 4-nitroquinoline 1-oxide. Oral Oncol 2001;37:579-585.

21. Focaccetti C, Bruno A, Magnani E, Bartolini D, Principi E, Dallaglio K, Bucci EO, Finzi G, Sessa F, Noonan DM, Albini A.Effects of 5-fluorouracil on morphology, cell 
cycle, proliferation, apoptosis, autophagy and ROS production in endothelial cells and cardiomyocytes. PLoS One 2015;10:1-9.

22. Yazbeck R, Lindsay R, Abbott CA, Benkendorff K, Howarth GS. Combined effects of muricid extract and 5-fluorouracil on intestinal toxicity in rats. Evid Based Complement Alternative Med 2015;6:33-40.

23. Chen L, Hu CS, Chen XZ, Hu GQ, Cheng ZB, Sun Y, Li WX, Chen YY, Xie FY, Liang SB, Chen Y, Xu TT, Li B, Long GX, Wang SY, Zheng BM, Guo Y, Sun Y, Mao YP, Tang LL, Chen YM, Liu MZ, Ma J.Concurrent chemoradiotherapy plus adjuvant chemotherapy versus concurrent chemoradiotherapy alone in patients with locoregionally advanced nasopharyngeal carcinoma: a phase 3 multicentre randomised controlled trial. The Lancet Oncol 2012;13:163-171.

24. Zhao H, Feng H, Liu D, Liu J, Ji N, Chen F, Luo X, Zhou Y, Dan H, Zeng X, Li J, Sun C, Meng J, Ju X, Zhou M, Yang H, Li L, Liang X, Chu L, Jiang L, He Y, Chen Q. Selfassembling monomeric nucleoside molecular nanoparticles loaded with 5-FU enhancing therapeutic efficacy against oral cancer. ACS nano 2015;9:9638-9651.
25. Choi EA, Lei H, Maron DJ, Mick R, Barsoum J, Yu QC, Fraker DL, Wilson JM, Spitz FR. .Combined 5-fluorouracil/systemic interferon- $\beta$ gene therapy results in long-term survival in mice with established colorectal liver metastases. Clin Cancer Res 2004;10:1535-1544.

26. Jiang Qq, Fan Ly, Yang Gl, Guo WH, Hou Wl, Chen Lj, Wie TQ. Improved therapeutic effectiveness by combining liposomal honokiol with cisplatin in lung cancer model. BMC Cancer 2008;8:242-248.

27. Arora S, Singh S, Piazza GA, Contreras CM, Panyam J, Singh AP. Honokiol: a novel natural agent for cancer prevention and therapy. Curr Mol Med 2012;12:1244-1252.

28. Pearson HE, Iida M, Orbuch RA, McDaniel NK, Nickel KP, Kimple RJ, Arbiser LJ, Wheeler LD. Overcoming resistance to cetuximab with honokiol, a small-molecule polyphenol. Mol Cancer Ther 2018;17:204-214.

29. Latif YA, El-Bana M, Hussein J, El-Khayat Z, Farrag AR. Effects of resveratrol in combination with 5-fluorouracil on N-methylnitrosourea-induced colon cancer in rats. Comp Clin Path 2019;28:1351-1362. 